\title{
Dr. Hughungs-Jackson.
}

The question seems to me to be an exceedingly large one, and to come to:a great extent to this: Do motor elements enter into the physical bases, or anatomical substrata, of mental states, otherwise consciousness? I have for inany years thought that they do. Since it is agreed upon that the lower parts of the nervous system are sensori-motor, I think it à priori likely that the higher parts, the physical bases of consciousness, are so too. The unit of constitution of the nervous system throughout is a sensori-motor unit. That would seem to me to agree with the doctrine of Evolution.

We have, as medical men, this problem:-Epilepsy being owing to disease of the cerebral cortex, and insanity being owing to a different kind of disease of the cerebral curtex, what is the constitution of "the organ of mind," the cerebrum, whereby two such different things result from disease of it, having regurd of course to the distinction between the physical and the psychical? Moreover, we have the two morbid states in sequence often enough. A man during an epileptic fit, if the primary discharge be strong enough, is stiffened into a rigid mass; after the fit he is temporarily insane. Further we have to show what are the anatomical and physiological conditions of the nervous system correlative with will, memory, reason, and emotion (together states of object consciousness). They are, I submit, activities of sensori-motor nervous arrangements - of nervous arrangements representing impressions and movements of parts of the body. We have also to find the physical differences answering to the differences between faint and vivid states of consciousness (object-consciousness). I submit that, neglecting differences in the sensory sphere, since no one denies the sensory element, the former occur during slight activities limited to the highest motor centres, and the latter during stronger activities of those centres overcoming lower motor centres and gaining the periphery. To my thinking, not only are the convolutions in the Rolandic region motor (middle motor centres) but also the convolutions in front, frontal or prefrontal lobes (highest motor centres). The physical process during ideation differs from that during perception (both being states of object consciousness), in that in the former lower motor centres are not overcome, and in the latter are.

There is no à priori reason why states of consciousness should not attend activities of motor as well as activities of sensory cells. It may seem easier to believe that sensations attend activities of sensury elcments than that they attend activities of mutor 
elements. The popular psychologist makes a confusion betwixt active states of sensory elements (physical states) and sensations (psychical states). Starting with what is purely physical, active states of sensory nerves, we get at length, in nervous centres, unconscious sensations (a contradictory expression) and then conscious sensations (a tautological expression). These sensations are then compounded in the highest centres into ideas. After that the popular psychologist inverts the process. Now ideas, sensations, and volitions (psychical states) produce movements (physical states); there is the expression "ideo-motor." In reality, movements result from liberations of energy, and not from states of consciousness.

The common expression "ideas of movements" is very objectionable. I would submit that there is no more an idea of a movement (in the sense either of ideas of states of muscles or of any motor or stnsory nervous elements representing any combination of muscles) than that, when I think of, or see a colour (coloured object), there is "an idea of" the retina or of any sensory centres representing it. I submit that we have psychical states attending activities of motor elements of the highest centres. For these psychical states there is no name, except in the case of words; words are psychical states attending activities of motor elements representing' certain very special and complex articulatory movements. (Strictly the nervous process is always sensori-motor.) I dwell on the motor element; no one denying the sensory element. I contend that when I make a movement with wy hand I have a peychical state just as certainly as I have another when I see that red chair. For if $I$ cut my arm off $I$ have a spectral hand remaining; that spectral hand I can move. This (certainly a psychical state although one uses the term "move") attends, I submit, activities of motor elements of my highest centres. When I cut my hand off I have a ghust of it, but of course that ghost was there when my arm was present. When a man who has lost a hand tries to pick up the reins of his horse with his ghostly hand, that " movement" of it occurs daring energising, beginning in the highest motor centres. Dr. Bastian would say that it occurred during activity of kinæsthetic centres. I admit, and am assuming, the activity of sensory elements, but I contend that there is activity of motor elements as well. I submit that the expressions " motor ideas," "ideas of movement," and " muscular sense" (if " muscular sensations" be intended) are illegitimate compounds of physiological and psychological terms.

I have often referred to the well-known displacements of external objects, in cases of ocular paralysis, in proof that psychical states 
attend activities of motor elements; but I find that these very cases are claimed by those who repudiate the " out-going current doctrine." I suppose the alterations in size of an after-image during changes of accommodation will be similarly claimed. The following, which I used to think a very strong thing favouring the doctrine that mental states attend activities of motor elements in the highest centres - the alteration in shape of after imageswill, I suppose, be claimed too. If we obtain an after-image of a square, and then project it on to an inclined sheet of paper, the spectral square becones oblong. There is here a change in muscular activity, but it may be said that no mental states attend activities of the motor nervous arrangements effecting it, but only of the sensory elements in activity from changes in the muscles put in action. Let us take an extreme case. A man has progressive muscular atrophy to the degree that he has no muscles in the right arm, and no anterior horns for them. Yet he localises a touch, and for the sake of argument I will grant that he does so as well as ever. I suppose the localisation implies movement, in this case the so-called "ideas of movement." It is true that the patient has no muscles, but the whole of his sensory nervous system is intact, and the whole of his motor nervous system with the exception stated. My submission is that the patient localises the impression becanse, besides sensory activities, there are also activities of his highest motor centres.

\section{Professor HorsLey.}

As some cases I have published have been introduced into this discussion, I shall be very glad of the opportunity to say something with respect to the representation of the " muscular sense" in the so-called motor region of the cortex. In the first place, let me say that if I use the terms usually employed, apparently with a twofold meanirg, I hope I shall not be misunderstood. Thus if $I$ speak of "sensation" I do not mean by that term, in every sense that I may use it, to connote consciousness. We are very much in want of a term to express better what is generally understood by the word sensation. The changes which go on in nerve endings when they are irritated require some other expression than our common word sensation, which conveys the meaning of the conscious perception of the process which is going on peripherally. If therefore I use the word "sensation," I hope to be understood that in a large majority of cases $I$ shall be referriug to a conscious perception of the changes in the nerve endings, but I may also mean the changes which go on in the nerve endings 